\title{
Comparison of balance ability and physical fitness according to the growth period in taekwondo players
}

\author{
Dong-Sung Choi', Eun-Na Jung ${ }^{2}$, Min-Hyuk Park ${ }^{1, *}$ \\ ${ }^{1}$ Center for Sport Science in Daegu, Daegu, Korea \\ ${ }^{2}$ Department of Sports Science, University of Seoul, Seoul, Korea
}

The purpose of this study was to investigate and evaluate balance ability, isokinetic moments, and physical fitness according to the growth period from middle school to university in male taekwondo players. Thirtyfive taekwondo players (middle school, $n=11$; high school, $n=15$; university, $n=9$ ) participated in this study. The anteriorposterior and medial-lateral CoP displacement at balance ability was better in university players than in high school and middle school players. The isokinetic knee joint muscle strength of the right extension and flexion \% body weight (BW) at $60 \%$ s was higher in university players than in high school players. The average power of right flexion BW at $180^{\circ} / \mathrm{sec}$ was higher in middle school players than in high school players. Back strength was higher in university players than in middle and high school players. The repeated jump was higher in high school players than in middle school players. The standing broad jump was higher in university players than in middle school players. The side-step was higher in university players than in high school players. The average power and total energy of anaerobic power were higher in university and high school players than in middle school players. The peak drop in anaerobic power was higher in middle school players than in high school players. Based on the results of the present study, the growth period should be considered when applying training such as balance, isokinetic moments, and physical fitness to male taekwondo players.

Keywords: Balance, Center of pressure, Foot pressure, Isokinetic strength, Physical fitness

\section{INTRODUCTION}

Foot skills used in the sports field are based on muscle strength centered on the knee joint of the human body, and landing or changing direction movement in jumping motion can cause a variety of injuries (Boden et al., 2000; Dick et al., 2007). In addition, due to the required skills of taekwondo, jumping and changing direction movements are important in taekwondo, and training programs to improve balance ability and prevent injury are needed for taekwondo players (Yoo et al., 2018).

Balance of the body is the ability to restore equilibrium with movement, and it is also important to perform the skills to maintain body posture or movement (Karlsson and Frykberg, 2000). In taekwondo competitions, the balance ability to maintain the center of gravity located within the base surface is important to improve performance. A previous study reported that balance ability plays an important role in maintaining posture and performing skills (Fong et al., 2012; Mak and Ng, 2003). One study observed that people with taekwondo training showed better balance skills than those without training (Leong et al., 2011). In particular, proprioceptive training has been shown to improve athletes' performances (Yoo et al., 2018). Proprioception training significantly improves the somatosensory movements of the body and is a key factor in improving balance and preventing injuries (Rivera et al., 2017).

Taekwondo players use isokinetic equipment to prevent injuries and design systematic training; children with developmental coordination disorder who received a taekwondo training program for 3 months improved their isokinetic knee strength at $180^{\circ} / \mathrm{sec}$ (Fong et al., 2013). In addition, as a result of studying the knees
*Corresponding author: Min-Hyuk Park (iD https://orcid.org/0000-0001-5204-5620 Center for Sport Science in Daegu, 127 Yunibeosiadeu-ro 42-gil, Suseong-gu, Daegu 42250, Korea

Email: pmh10004@naver.com

Received: August 26, 2021 / Accepted: September 16, 2021
This is an Open Access article distributed under the terms of the Creative Commons Attribution Non-Commercial License (https://creativecommons.org/licenses/by-nc/4.0/) which permits unrestricted non-commercial use, distribution, and reproduction in any medium, provided the original work is properly cited. 
of female collegiate taekwondo players for 1 year, the peak power of the right flexor was significantly increased (Kim et al., 2015).

Taekwondo plays an important role in physical fitness factors. Anaerobic testing of taekwondo athletes revealed characteristics that distinguish different levels of taekwondo athletes (Tayech et al., 2020). Anaerobic testing not only allows researchers to identify excellent athletes, but also plays an important role in identifying the ability of the lower extremities to attack the opponent with quick movements (Valenzuela et al., 2020). Back strength is reliant on core muscles, and a previous study showed that core training had a positive effect on the balance ability of athletes (Hammami et al., 2016).

As mentioned above, many previous studies have compared and analyzed balance ability, isokinetic moments, and physical fitness in taekwondo players, but there is a lack of studies comparing and analyzing changes in the growth period of players in the middle school, high school, and university taekwondo players. If we could examine changes in balance ability, physical fitness, etc. over the period of growth in taekwondo players, it could be possible to utilize an injury prevention program and customized physical strength enhancement according to the growth period in taekwondo players.

Therefore, the purpose of this study was to evaluate balance ability, isokinetic moments, and physical strength depending on the growth period in the middle, high, and university's taekwondo players, to identify the characteristics of each player based on these factors, and to determine how these factors affect balance ability and physical strength. Based on this, another purpose of this study was to provide systematic level training programs and data for preventing injuries to growing taekwondo players in the middle school, high school, and university.

\section{MATERIALS AND METHODS}

\section{Subjects}

Male middle school, high school, and university taekwondo players who lived in Daegu city were recruited as subjects for this study. They had no injury experience within 6 months and could be measured for this study. Subjects were divided into middle school $(\mathrm{n}=11)$, high school $(\mathrm{n}=15)$, and university $(\mathrm{n}=9)$. All subjects were asked to write a written informed consent form, and a Physical Activity Readiness Questionnaire (PAR-Q) test was conducted. The physical characteristics of the subjects are presented in Table 1.

In this study, we used the G-power program to calculate the target number of subjects. As a result, the effect size was 0.7109283 , $\alpha$ (significant level) was 0.05 , and the power of test $(1-\beta)$ was $80 \%$.
Table 1. Physical characteristics of the subjects

\begin{tabular}{lccc} 
Variable & $\begin{array}{c}\text { Middle school } \\
(\mathrm{n}=11)\end{array}$ & $\begin{array}{c}\text { High school } \\
(\mathrm{n}=15)\end{array}$ & $\begin{array}{c}\text { University } \\
(\mathrm{n}=9)\end{array}$ \\
\hline Age $(\mathrm{yr})$ & $14.60 \pm 0.50$ & $17.90 \pm 1.00$ & $21.10 \pm 1.20$ \\
Height $(\mathrm{cm})$ & $168.20 \pm 7.00$ & $177.00 \pm 5.90$ & $181.10 \pm 6.20$ \\
Weight $(\mathrm{kg})$ & $60.10 \pm 9.00$ & $68.90 \pm 10.00$ & $78.20 \pm 17.20$ \\
\% Body fat $(\%)$ & $12.30 \pm 4.10$ & $12.70 \pm 3.80$ & $14.70 \pm 4.80$ \\
\hline
\end{tabular}

Values are presented as mean \pm standard deviation.

Based on this, a total of 24 subjects were calculated to use one-way analysis of variance (ANOVA) to compare balance ability, isokinetic moments, anaerobic ability, and physical fitness of each group (Bakall'ár et al., 2020). Therefore, in this study, 35 subjects were selected based on the dropout rate.

\section{Balance test}

Wireless foot pressure equipment (OpenGo insole system, Moticon Co., München, Germany) was used for the balance test, and the center of pressure $(\mathrm{CoP})$ displacement was measured with a single-leg stance. All subjects were asked to put an insole-type sensor in their shoes, and then they performed a single-leg stance with their eyes open. The position of measurement was to stand in a fixed position, with both hands on the pelvis, and one foot in balance supporting the floor while maintaining a $90^{\circ}$ flexed knee position on the opposite leg. The measurement time was $30 \mathrm{sec}$ for both feet, and the measurements were conducted 3 times in total. The sampling frequency of the plantar pressure equipment was $50 \mathrm{~Hz}$, and the insole-type sensor was tailored to fit the feet of all subjects. The anteriorposterior and medial-lateral $\mathrm{CoP}$ displacement of the right and left feet were measured with a singleleg stance. All data of the anteriorposterior $(\mathrm{Y})$ and medial-lateral (X) CoP displacement of both feet were analyzed using the Moticon OpenGo program (OpenGo insole system, Moticon Co., München, Germany). The balance test was performed 3 times for each foot, and the average values were used in the analysis.

\section{Isokinetic moments test}

The isokinetic muscle-joint measurement system (HUMAC NORM Isokinetic Extremity System, Computer Sports Medicine Inc., Stoughton, MA, USA) was used to measure the isokinetic muscle strength and muscle power of the knee joint. Isokinetic moments measured the extension and flexion muscle function of the knee joint at $60 \%$ sec and $180^{\circ}$ sec of angular velocity, followed by the measurement procedure of the CSMI (HUMAC NORM Isokinetic Extremity System, Computer Sports Medicine 
Table 2. Change of balance ability

\begin{tabular}{|c|c|c|c|c|c|c|}
\hline \multirow{2}{*}{ Measurement factor } & \multicolumn{3}{|c|}{ Group } & \multirow{2}{*}{$F$-value } & \multirow{2}{*}{$P$-value } & \multirow{2}{*}{ Scheffe } \\
\hline & Middle school $^{\mathrm{a}}$ & High school $^{\mathrm{b}}$ & University $^{c}$ & & & \\
\hline Right anteriorposterior CoP displacement (mm) & $15.53 \pm 13.70$ & $-18.27 \pm 10.33$ & $-2.39 \pm 13.54$ & 4.40 & $0.022^{*}$ & $\mathrm{a}=\mathrm{b}<\mathrm{c}=\mathrm{a}$ \\
\hline Right medial-lateral CoP displacement (mm) & $-5.91 \pm 2.47$ & $-4.86 \pm 1.61$ & $-13.74 \pm 3.25$ & 36.95 & $0.000^{* * *}$ & $a=b>c$ \\
\hline Left anteriorposterior CoP displacement (mm) & $15.94 \pm 12.31$ & $-14.15 \pm 10.46$ & $0.03 \pm 10.60$ & 5.86 & $0.007^{* *}$ & $a=b<c$ \\
\hline Left medial-lateral CoP displacement (mm) & $6.11 \pm 3.82$ & $4.58 \pm 2.55$ & $-10.31 \pm 2.87$ & 79.93 & $0.000^{* * *}$ & $a=b>c$ \\
\hline
\end{tabular}

Values are presented as mean \pm standard deviation.

${ }^{*} P<0.05 .{ }^{* *} P<0.01 .{ }^{* * *} P<0.001$.

Inc., Stoughton, MA, USA). All subjects performed the movement 3 times, and both extension and flexion muscle strength of both feet were evaluated at angular velocities of $60 \%$ sec and $180 \%$ sec. Isokinetic muscle strength was measured with extension and flexion movements of the dominant leg of the knee joint at an angular velocity of $60^{\circ} / \mathrm{sec}$. After the measurement was performed on the dominant leg 3 times each with a 1-min break, the opposite leg was measured using the same procedure as that used for the dominant leg. After the isokinetic muscle power was set equally at an angular velocity of $180 \% \mathrm{sec}$, the extension and flexion movements of the knee joint were performed 5 times each on the dominant leg.

\section{Physical fitness test}

Back muscle strength (ST-5402D, SidTech Co., Bucheon, Korea), sit-up (FAS-5370, Faskorea Co., Incheon, Korea), repeated jump (FAS-5310, Faskorea Co.), standing long jump (FT-7700, Faskorea Co.); sergent jump (ST-150, SidTech Co.), whole body reaction (ST-140, SidTech Co.), side-step (ST-110, SidTech Co.), trunk forward flexion (DHT-5412, Takei Scientific Instruments Co., Niigata, Japan), trunk backward flexion (TKK-5404, Takei Scientific Instruments Co.), and anaerobic power (Monark 894E, Monark Exercise AB, Vansbro, Sweden) were measured in the physical fitness test.

\section{Data analysis and processing}

Normality of distribution in each category was determined using the Shapiro-Wilk test. All data in each group showed normal distribution. All data were analyzed using IBM SPSS Statistics ver. 21.0 (IBM Co., Armonk, NY, USA). One-way ANOVA was performed to compare and analyze the balance ability, isokinetic moments, and physical fitness of male taekwondo players in middle school, high school, and university, and post hoc tests were performed by Scheffe. The significance level of all data was set at $\alpha=0.05$.

\section{RESULTS}

\section{Effect of balance ability}

The results of balance ability are shown in Table 2 . The anteriorposterior $\mathrm{CoP}$ displacement on the right foot showed a statistically significant difference between the groups $(F=4.40, P<0.05)$. As a result of post hoc tests, the high school players had the $\mathrm{CoP}$ displacement more posteriorly than the university players $(P<0.05)$. The medial-lateral $\mathrm{CoP}$ displacement on the right foot showed a statistically significant difference between the groups $(F=36.95$, $P<0.001)$. As a result of post hoc tests, the university players had the $\mathrm{CoP}$ displacement more laterally than the high school $(P<0.001)$ and middle school $(P<0.001)$ players. The anteriorposterior $\mathrm{CoP}$ displacement on the left foot showed a statistically significant difference between the groups $(F=5.86, P<0.01)$. As a result of post boc tests, the high school $(P<0.05)$ and middle school $(P<0.05)$ players had the $\mathrm{CoP}$ displacement more posteriorly than the university players. In addition, the medial-lateral $\mathrm{CoP}$ displacement on the left foot showed a statistically significant difference between groups $(F=79.93, P<0.001)$. As a result of post hoc tests, the university players had the $\mathrm{CoP}$ displacement more laterally than the high $(P<0.001)$ and middle $(P<0.001)$ school players.

\section{Effect of isokinetic moments test}

The results of isokinetic muscle function at angular velocity $60 \%$ sec are shown in Table 3. Isokinetic muscle strength measurement in the knee joint and right extension muscle strength per weight showed a statistically significant difference between the groups $(F=4.29, P<0.05)$. The post boc tests showed that the university players were stronger than the high school players $(P<0.05)$. Both right extension muscle strength $(F=7.81, P<0.01)$ and left extension muscle strength $(F=9.52, P<0.01)$ were significantly different between the groups. Post hoc tests showed that both right and left extension muscle strength in the university players were stronger than those in the middle school $(P<0.01)$ and high school 
Table 3. Results of Isokinetic muscle function at angular velocity of $60^{\circ} / \mathrm{sec}$

\begin{tabular}{|c|c|c|c|c|c|c|}
\hline \multirow{2}{*}{ Measurement factor } & \multicolumn{3}{|c|}{ Group } & \multirow{2}{*}{$F$-value } & \multirow{2}{*}{$P$-value } & \multirow{2}{*}{ Scheffe } \\
\hline & Middle school $^{a}$ & High school ${ }^{b}$ & University ${ }^{c}$ & & & \\
\hline Right extensor muscle strength (\% BW) & $260.00 \pm 24.80$ & $237.30 \pm 37.20$ & $274.70 \pm 27.40$ & 4.29 & $0.022^{*}$ & $\mathrm{a}=\mathrm{b}<\mathrm{c}=\mathrm{a}$ \\
\hline Left extensor muscle strength (\% BW) & $243.70 \pm 30.40$ & $233.40 \pm 34.80$ & $265.10 \pm 37.40$ & 2.43 & 0.104 & $a=b=c$ \\
\hline Right extensor muscle strength (Nm) & $157.20 \pm 30.30$ & $163.30 \pm 32.30$ & $213.80 \pm 43.80$ & 7.81 & $0.002^{* *}$ & $a=b<c$ \\
\hline Left extensor muscle strength (Nm) & $147.30 \pm 33.10$ & $160.30 \pm 27.50$ & $203.70 \pm 29.90$ & 9.52 & $0.001^{* *}$ & $a=b<c$ \\
\hline Right flexor muscle strength (\% BW) & $141.90 \pm 18.80$ & $128.20 \pm 19.70$ & $153.00 \pm 26.70$ & 3.93 & $0.030^{*}$ & $\mathrm{a}=\mathrm{b}<\mathrm{c}=\mathrm{a}$ \\
\hline Left flexor muscle strength (\% BW) & $137.80 \pm 17.90$ & $132.40 \pm 23.50$ & $143.00 \pm 21.20$ & 0.71 & 0.497 & $a=b=c$ \\
\hline Right flexor muscle strength (Nm) & $85.40 \pm 16.80$ & $88.10 \pm 17.20$ & $117.70 \pm 22.90$ & 9.10 & $0.001^{* *}$ & $a=b<c$ \\
\hline Left flexor muscle strength (Nm) & $82.40 \pm 14.20$ & $90.40 \pm 16.70$ & $109.60 \pm 13.50$ & 8.28 & $0.001^{* *}$ & $a=b<c$ \\
\hline Right extensor/flexor ratio (\%) & $54.60 \pm 7.10$ & $54.50 \pm 7.80$ & $55.30 \pm 6.04$ & 0.04 & 0.963 & $a=b=c$ \\
\hline Left extensor/flexor ratio (\%) & $56.80 \pm 7.10$ & $56.90 \pm 7.70$ & $54.40 \pm 6.90$ & 0.36 & 0.700 & $a=b=c$ \\
\hline Difference of right-left extensor muscle strength (\%) & $8.30 \pm 5.90$ & $8.50 \pm 7.30$ & $12.30 \pm 9.80$ & 0.88 & 0.423 & $a=b=c$ \\
\hline Difference of right-left flexor muscle strength (\%) & $9.30 \pm 7.00$ & $9.10 \pm 7.90$ & $8.90 \pm 6.80$ & 0.01 & 0.993 & $a=b=c$ \\
\hline
\end{tabular}

Values are presented as mean \pm standard deviation.

BW, body weight.

${ }^{*} P<0.05 .{ }^{*} P<0.01$.

Table 4. Results of Isokinetic muscle function at angular velocity of $180^{\circ} / \mathrm{sec}$

\begin{tabular}{|c|c|c|c|c|c|c|}
\hline \multirow{2}{*}{ Measurement factor } & \multicolumn{3}{|c|}{ Group } & \multirow{2}{*}{ F-value } & \multirow{2}{*}{$P$-value } & \multirow{2}{*}{ Scheffe } \\
\hline & Middle school $^{\mathrm{a}}$ & High school $^{b}$ & University ${ }^{c}$ & & & \\
\hline Mean power of right extensor muscle (\% BW) & $290.60 \pm 31.10$ & $276.60 \pm 44.80$ & $292.10 \pm 28.90$ & 0.67 & 0.518 & $a=b=c$ \\
\hline Mean power of left extensor muscle (\% BW) & $279.90 \pm 33.10$ & $257.70 \pm 59.00$ & $287.30 \pm 24.90$ & 1.46 & 0.248 & $a=b=c$ \\
\hline Mean power of right extensor muscle (Watts) & $174.90 \pm 34.20$ & $190.30 \pm 38.50$ & $225.20 \pm 31.60$ & 5.14 & $0.012^{*}$ & $\mathrm{~b}=\mathrm{a}<\mathrm{c}=\mathrm{b}$ \\
\hline Mean power of left extensor muscle (Watts) & $169.20 \pm 37.30$ & $176.40 \pm 44.30$ & $222.30 \pm 37.10$ & 5.00 & $0.013^{*}$ & $a=b<c$ \\
\hline Mean power of right flexor muscle (\% BW) & $188.20 \pm 28.60$ & $148.30 \pm 39.20$ & $181.10 \pm 45.10$ & 4.90 & $0.026^{*}$ & $c=b<a=c$ \\
\hline Mean power of left flexor muscle (\% BW) & $185.50 \pm 28.10$ & $169.70 \pm 45.70$ & $175.30 \pm 39.80$ & 0.51 & 0.604 & $a=b=c$ \\
\hline Mean power of right flexor muscle (W) & $113.10 \pm 23.90$ & $102.00 \pm 30.00$ & $137.60 \pm 23.90$ & 5.00 & $0.013^{*}$ & $\mathrm{a}=\mathrm{b}<\mathrm{c}=\mathrm{a}$ \\
\hline Mean power of left flexor muscle (W) & $112.20 \pm 28.20$ & $116.30 \pm 33.20$ & $134.90 \pm 28.50$ & 1.54 & 0.230 & $a=b=c$ \\
\hline Difference of right-left extensor muscle power (\%) & $7.50 \pm 3.60$ & $10.40 \pm 13.80$ & $7.70 \pm 5.20$ & 0.36 & 0.701 & $a=b=c$ \\
\hline Difference of right-left flexor muscle power (\%) & $10.70 \pm 8.40$ & $14.90 \pm 13.00$ & $11.90 \pm 9.20$ & 0.51 & 0.608 & $a=b=c$ \\
\hline
\end{tabular}

Values are presented as mean \pm standard deviation.

BW, body weight.

${ }^{*} P<0.05$.

$(P<0.01)$ players. Right flexion muscle strength per weight was significantly different between the groups $(F=3.93, P<0.05)$. The post hoc tests showed that the university players were stronger than the high school players $(P<0.05)$. The right $(F=9.10, P<0.01)$ and left $(F=8.28, P<0.01)$ flexion muscle strength showed a statistically significant difference between the groups. As a result of post hoc tests, right flexion muscle strength in the university players was stronger than in the middle school $(P<0.01)$ and high school $(P<0.01)$ players, and the left flexion muscle strength in the university players was stronger than that in the middle school $(P<0.01)$ and high school $(P<0.05)$ players.

The results of isokinetic muscle function at angular velocity $180^{\circ} / \mathrm{sec}$ are shown in Table 4 . The mean isokinetic muscle power in the knee joint and the mean of the right extension muscle power showed a statistically significant difference between the groups $(F=5.14, P<0.05)$. Post hoc tests showed that university players had higher scores than middle school players $(P<0.05)$. The mean left extension muscle power showed a statistically significant difference between the groups $(F=5.00, P<0.05)$. Post hoc tests showed that university players showed higher scores than middle $(P<0.05)$ and high $(P<0.05)$ school players. The mean of right per weight flexion muscle power showed a statistically significant difference between the groups $(F=4.90, P<0.05)$. As a result of post hoc tests, middle school players showed higher scores than high school players 
Table 5. Result of physical fitness measurement

\begin{tabular}{|c|c|c|c|c|c|c|}
\hline \multirow{2}{*}{ Measurement factor } & \multicolumn{3}{|c|}{ Group } & \multirow{2}{*}{$F$-value } & \multirow{2}{*}{$P$-value } & \multirow{2}{*}{ Scheffe } \\
\hline & Middle school $^{\mathrm{a}}$ & High school $^{b}$ & University $^{c}$ & & & \\
\hline Back muscle strength (kg) & $98.90 \pm 17.20$ & $118.80 \pm 19.10$ & $147.90 \pm 19.20$ & 17.38 & $0.000^{* * *}$ & $a<b ; a, b<c$ \\
\hline Sit-up (trial) & $51.70 \pm 9.20$ & $52.60 \pm 8.50$ & $50.80 \pm 7.10$ & 0.13 & 0.875 & $a=b=c$ \\
\hline Repeated jump (trial/30 sec) & $50.50 \pm 4.80$ & $55.10 \pm 3.20$ & $53.30 \pm 3.00$ & 4.84 & $0.015^{*}$ & $c=a<b=c$ \\
\hline Standing long jump (cm) & $210.90 \pm 9.20$ & $221.00 \pm 18.20$ & $233.50 \pm 16.60$ & 5.27 & $0.011^{*}$ & $\mathrm{~b}=\mathrm{a}<\mathrm{c}=\mathrm{b}$ \\
\hline Sargent jump (cm) & $50.20 \pm 4.80$ & $50.80 \pm 5.00$ & $53.60 \pm 4.30$ & 1.40 & 0.261 & $a=b=c$ \\
\hline Full-body reaction-sound (sec) & $0.20 \pm 0.02$ & $0.20 \pm 0.00$ & $0.24 \pm 0.03$ & 0.20 & 0.823 & $a=b=c$ \\
\hline Full-body reaction-light (sec) & $0.30 \pm 0.02$ & $0.30 \pm 0.00$ & $0.25 \pm 0.03$ & 1.25 & 0.299 & $a=b=c$ \\
\hline Side-step (trial/20 sec) & $48.70 \pm 3.80$ & $48.30 \pm 3.80$ & $52.40 \pm 2.40$ & 4.31 & $0.022^{*}$ & $a=b<c=a$ \\
\hline Trunk forward flexion with sitting (cm) & $15.50 \pm 5.70$ & $18.70 \pm 6.10$ & $16.80 \pm 5.20$ & 1.00 & 0.378 & $a=b=c$ \\
\hline Trunk backward flexion (cm) & $53.60 \pm 6.50$ & $58.10 \pm 7.20$ & $56.50 \pm 4.40$ & 1.57 & 0.224 & $a=b=c$ \\
\hline Maximum anaerobic power (W) & $484.20 \pm 93.10$ & $573.80 \pm 108.90$ & $593.50 \pm 132.30$ & 2.98 & 0.065 & $a=b=c$ \\
\hline Maximum anaerobic power (W/kg) & $8.10 \pm 1.00$ & $8.20 \pm 0.70$ & $7.60 \pm 1.00$ & 1.33 & 0.279 & $a=b=c$ \\
\hline Mean of anaerobic power (W) & $357.10 \pm 60.20$ & $443.70 \pm 78.80$ & $453.30 \pm 90.90$ & 5.23 & $0.011^{*}$ & $\mathrm{a}<\mathrm{b}=\mathrm{c}$ \\
\hline Anaerobic total energy (J) & $10,033.70 \pm 1,577.00$ & $12,854.50 \pm 2,221.50$ & $12,927.80 \pm 2,498.50$ & 6.81 & $0.003^{* *}$ & $a<b=c$ \\
\hline Anaerobic peak drop (\%) & $55.60 \pm 7.70$ & $46.70 \pm 6.80$ & $52.50 \pm 7.20$ & 5.10 & $0.012^{*}$ & $\mathrm{c}=\mathrm{b}<\mathrm{a}=\mathrm{c}$ \\
\hline
\end{tabular}

Values are presented as mean \pm standard deviation.

${ }^{*} P<0.05$. ${ }^{* *} P<0.01$. ${ }^{* *} P<0.001$.

$(P<0.05)$. The mean right flexion muscle power showed a statistically significant difference between the groups $(F=5.00, P<0.05)$. As a result of post hoc tests, the university players showed higher scores than the high school players $(P<0.05)$.

\section{Effect of physical fitness test}

The results of physical fitness measurement are shown in Table 5. The back muscle strength test showed a statistically significant difference between the groups $(F=17.38, P<0.001)$. As a result of post hoc tests, the high school players were stronger than the middle school players $(P<0.05)$, and the university players showed stronger results than the middle school $(P<0.001)$ and high school $(P<0.001)$ players. A repeated jump test showed a statistically significant difference between the groups $(F=4.84, P<0.05)$. As a result of post hoc tests, the high school players showed higher scores than the middle school players $(P<0.05)$. The standing long jump test showed a statistically significant difference between the groups ( $F=5.27, P<0.05)$. Post hoc tests showed that university players had higher scores than middle school players $(P<0.05)$. The side-step test showed a statistically significant difference between the groups $(F=4.31, P<0.05)$. The post hoc tests showed that the university players were faster than the high school players $(P<0.05)$.

Anaerobic power, mean anaerobic power $(F=5.23, P<0.05)$, anaerobic total energy $(F=6.81, P<0.01)$, and anaerobic peak drop
$(F=5.10, P<0.05)$ were significantly different among the three groups. As a result of post hoc tests, the high school $(P<0.05)$ players and the university $(P<0.05)$ players showed higher mean anaerobic power than middle school players. High $(P<0.01)$ school players and university players $(P<0.05)$ showed higher total anaerobic energy than middle school players. Finally, the middle school players showed a higher anaerobic peak drop than the high school players $(P<0.05)$.

\section{DISCUSSION}

This study was conducted to compare balance ability, isokinetic moments in the knee joint, and physical fitness according to the growth period among male middle and high school and university taekwondo players, and to provide a systematic training program for improving their performance and data to prevent injury.

Balance is the ability to maintain body movement (Karlsson and Frykberg, 2000), and based on input information from vision, vestibular sense, and proprioceptive sense, it is done by regulating body position and movement in the central nervous system (Röijezon et al., 2015). Posture control during a single-leg stance is an essential factor in physical activity and performance improvement (Jonsson et al., 2004). In this study, the high school taekwondo players showed a change in the right anteriorposterior CoP displacement more posteriorly from the center of the foot than the 
university taekwondo players. Postural control is defined as the ability to minimize or stabilize gravitational centric movement within the base of support to maintain balance (Karlsson and Frykberg, 2000; Tsai et al., 2006). Therefore, during the singleleg stance, the $\mathrm{CoP}$ of the supporting foot is located at the center of the foot. This can minimize the center of gravity within the base of the support, which will have a positive effect on balance. After all, university players have an advantage over high school players in terms of physical control. Therefore, high school taekwondo players will have to work to stabilize the right anteriorposterior $\mathrm{CoP}$ displacement. Previous studies have reported that proprioceptive training (Dias et al., 2011; Romero-Franco et al., 2012) and core training (Hibbs et al., 2008) are needed to improve balance skills of taekwondo players. Both the middle and high school taekwondo players showed a change in the left anteriorposterior $\mathrm{CoP}$ displacement more posteriorly than the university taekwondo players. These results indicate that university players are better at physical control than middle and high school players. The university taekwondo players showed a change in both the right and left medial-lateral CoP displacement more laterally than the middle and high school taekwondo players. Based on the principle of static stability, a wider supporting surface is reported to be more stable than a narrow support plane (Bressel et al., 2007; Lugade et al., 2011), and the foot is characterized by a narrower inner supporting surface than the outer supporting surface due to the foot arch. After all, if the $\mathrm{CoP}$ displacement is located on the outer side rather than on the inner side, it could have a positive effect on stability; therefore, university players have an advantage over middle and high school players in terms of physical control. Regarding the principle of static stability, it has been reported that the presence of the center of mass at the bottom is more stable (Bressel et al., 2007). However, in our study, university players with a higher center of movement had a more positive effect on their balance ability than middle and high school players. This result is believed to be due to the strengthening of lower extremity muscles and muscle power in university players.

As a result of isokinetic muscle strength in the knee joint, the university players had stronger right extensor muscle strength per weight than the high school players, and the university players had stronger right and left isokinetic extensor muscle strength in the knee joint than the middle and high school players. These results indicate that university players had better extensor muscle strength in the knee joint than the other two groups. Taekwondo players need strong physical strength; in particular, they use their lower extremities. In order to show maximum power in the kick- ing movement, the knee and hip joints need to be extended, which requires activation of the extensor muscles of the knee and hip joints (Kim et al., 2011). After all, middle and high school players who are growing must continue to work hard to strengthen their extensor muscle in the knee joint until they grow into university players (Øiestad et al., 2015). However, it is only natural that extension muscle strength in the knee joint varies with the growth period (Hansen et al., 1999). Given the lack of statistical difference between middle and high school players, high school players will have to make special efforts to strengthen their extensor muscle strength in the knee joint.

The university players had stronger right flexor muscle strength per weight in the knee joint than the high school players, and the university players had stronger right and left flexor muscle strength in the knee joint than the middle and high school players. Athletes show differences in knee joint flexor muscle strength depending on their growth period (Ellenbecker et al., 2007). Flexor muscle strength in the knee joint relies on the hamstring muscles, including the semitendinous, semimembranosus, and biceps femoris muscles in the knee joint, and they perform the function of moving the body when walking or running. Moreover, the relative weakness of the extension/flexion ratio in the hamstrings increases the incidence of anterior cruciate ligament rupture (Kannus and Järvinen, 1990).

The university players had better means of isokinetic muscle power than middle and high school players. However, middle school players had a higher mean of right isokinetic flexor muscle power per weight than the high school players, and the university players had a higher mean of right isokinetic flexor muscle power than the high school players. Taekwondo players attacking skills by making power at the moment are more important than anything else; therefore, the power of the lower extremities is an important factor in performance (Valenzuela et al., 2020). Taekwondo players in their growth period need training to improve their lower extremities; in particular, high school players are expected to need more training.

The high school players had stronger back muscle strength than the middle school players, and the university players had stronger back muscle strength than both the middle and high school players. Back muscle strength relies on the core muscles, and a previous study reported that core training positively affects an athlete's balance ability positively (Hammami et al., 2016). Therefore, back muscle strength is considered to have a positive effect on balance ability. High school players had higher number of repeated jumps than middle school players. The university players had a longer 
standing long jump than middle school players. These results support the results of a previous study in which university taekwondo players showed longer standing long jumps than taekwondo players during their growth period. Taekwondo players' skills to attack opponents by making instantaneous power movements are paramount, so the power of the lower extremities is an important factor for their performance (Valenzuela et al., 2020). Therefore, middle school players will have to continue training to strengthen their lower extremities. The university players had faster side steps than the high school players. Agility is the ability to quickly change direction (Miranda et al., 2016). It is a very important factor of physical strength for taekwondo players, and if they can increase their target score through a quick turnaround movement, it will have a positive effect on improving their taekwondo performance.

In conclusion, there were differences in balance ability, isokinetic moments in the knee joint, back muscle strength, lower body muscle endurance, agility, and quickness ability according to the growth period among middle school, high school, and university taekwondo players. It is believed that the growth period should be considered when applying training such as balance, isokinetic moments, and basic physical fitness to male taekwondo players. If a follow-up study tried to analyze and compare balance ability, isokinetic moments in the knee joint, and basic physical fitness according to the growth period of female taekwondo players, it could provide detailed data for improving the performance of female taekwondo players and using effective rehabilitation and training programs.

\section{CONFLICT OF INTEREST}

No potential conflicts of interest relevant to this article were reported.

\section{ACKNOWLEDGMENTS}

The authors received no financial support for this article.

\section{REFERENCES}

Bakallár I, Šimonek J, Kanásová J, Krčmárová B, Krčmár M. Multiple athletic performances, maturation, and Functional Movement Screen total and individual scores across different age categories in young soccer players. J Exerc Rehabil 2020;16:432-441.

Boden BP, Dean GS, Feagin JA, Garrett WE. Mechanisms of anterior cruciate ligament injury. Orthopedics 2000;23:573-578.
Bressel E, Yonker JC, Kras J, Heath EM. Comparison of static and dynamic balance in female collegiate soccer, basketball, and gymnastics athletes. J Athl Train 2007;42:42-46.

Dias A, Pezarat-Correia P, Esteves J, Fernandes O. The influence of a balance training program on the electromyographic latency of the ankle musculature in subjects with no history of ankle injury. Phys Ther Sport 2011;12:87-92.

Dick R, Putukian M, Agel J, Evans TA, Marshall SW. Descriptive epidemiology of collegiate women's soccer injuries: National Collegiate Athletic Association Injury Surveillance System, 1988-1989 through 2002-2003. J Athl Train 2007;42:278-285.

Ellenbecker TS, Roetert EP, Sueyoshi T, Riewald S. A descriptive profile of age-specific knee extension flexion strength in elite junior tennis players. Br J Sports Med 2007;41:728-732.

Fong SS, Chung JW, Chow LP, Ma AW, Tsang WW. Differential effect of Taekwondo training on knee muscle strength and reactive and static balance control in children with developmental coordination disorder: a randomized controlled trial. Res Dev Disabil 2013;34:1446-1455.

Fong SS, Fu SN, Ng GY. Taekwondo training speeds up the development of balance and sensory functions in young adolescents. J Sci Med Sport 2012;15:64-68.

Hammami R, Chaouachi A, Makhlouf I, Granacher U, Behm DG. Associations between balance and muscle strength, power performance in male youth athletes of different maturity status. Pediatr Exerc Sci 2016; 28:521-534.

Hansen L, Bangsbo J, Twisk J, Klausen K. Development of muscle strength in relation to training level and testosterone in young male soccer players. J Appl Physiol 1999;87:1141-1147.

Hibbs AE, Thompso KG, French D, Wrigley A, Spear I. Optimizing performance by improving core stability and core strength. Am J Sports Med 2008;38:995-1008.

Jonsson E, Seiger A, Hirschfeld H. One-leg stance in healthy young and elderly adults: a measure of postural steadiness? Clin Biomech 2004; 19:688-694

Kannus P, Järvinen M. Knee flexor/extensor strength ratio in follow-up of acute knee distortion injuries. Arch Phys Med Rehabil 1990;71:38-41.

Karlsson A, Frykberg G. Correlations between force plate measures for assessment of balance. Clin Biomech 2000;15:365-369.

Kim HB, Jung HC, Song JK, Chai JH, Lee EJ. A follow-up study on the physique, body composition, physical fitness, and isokinetic strength of female collegiate Taekwondo athletes. J Exerc Rehabil 2015;11:57-64.

Kim YK, Kim YH, Im SJ. Inter-joint coordination in producing kicking velocity of taekwondo kicks. J Sports Sci Med 2011;10:31-38.

Leong HT, Fu SN, Ng GY, Tsang WW. Low-level Taekwondo practitioners have better somatosensory organisation in standing balance than sed- 
entary people. Eur J Appl Physiol 2011;111:1787-1793.

Lugade V, Lin V, Chou LS. Center of mass and base of support interaction during gait. Gait Posture 2011;33:406-411.

Mak MK, Ng PL. Mediolateral sway in single-leg stance is the best discriminator of balance performance for Tai-Chi practitioners. Arch Phys Med Rehabil 2003;84:683-686.

Miranda DL, Hsu WH, Gravelle DC, Petersen K, Ryzman R, Niemi J, Lesniewski-Laas N. Sensory enhancing insoles improve athletic performance during a hexagonal agility task. J Biomech 2016;49:1058-1063.

Øiestad BE, Juhl CB, Eitzen I, Thorlund JB. Knee extensor muscle weakness is a risk factor for development of knee osteoarthritis. A systematic review and meta-analysis. Osteoarthritis Cartilage 2015;23:171-177.

Rivera MJ, Winkelmann ZK, Powden CJ, Games KE. Proprioceptive training for the prevention of ankle sprains: an evidence-based review. J Athl Train 2017;52:1065-1067.

Röijezon U, Clark NC, Treleaven J. Proprioception in musculoskeletal rehabilitation. Part 1: Basic science and principles of assessment and clinical interventions. Man Ther 2015;20:368-377.

Romero-Franco N, Martínez-López E, Lomas Vega R, Hita-Contreras F,
Martínez-Amat A. Effects of proprioceptive training program on core stability and center of gravity control in sprinters. J Strength Cond Res 2012;26:2071-2077.

Tayech A, Mejri MA, Chaouachi M, Chaabene H, Hambli M, Brughelli M, Behm DG, Chaouachi A. Taekwondo anaerobic intermittent kick test: discriminant validity and an update with the gold-standard wingate test. J Hum Kinet 2020;31:229-242.

Tsai LC, Yu B, Mercer VS, Gross MT. Comparison of different structural foot types for measures of standing postural control. J Orthop Sports Phys Ther 2006;36:942-953.

Valenzuela PL, McGuigan M, Sánchez-Martínez G, Torrontegi E, VázquezCarrión J, Montalvo Z, Abad CCC, Pereira LA, Loturco I. Reference power values for the jump squat exercise in elite athletes: a multicenter study. J Sports Sci 2020;38:2273-2278.

Yoo S, Park SK, Yoon S, Lim HS, Ryu J. Comparison of proprioceptive training and muscular strength training to improve balance ability of taekwondo Poomsae athletes: a randomized controlled trials. J Sports Sci Med 2018;17:445-454. 